\title{
Burn wound healing and treatment: review and advancements
}

\author{
Matthew P. Rowan ${ }^{1 *}$, Leopoldo C. Cancio ${ }^{1}$, Eric A. Elster ${ }^{2}$, David M. Burmeister ${ }^{1}$, Lloyd F. Rose ${ }^{1}$, \\ Shanmugasundaram Natesan ${ }^{1}$, Rodney K. Chan ${ }^{1,3}$, Robert J. Christy ${ }^{1}$ and Kevin K. Chung ${ }^{1,2}$
}

\begin{abstract}
Burns are a prevalent and burdensome critical care problem. The priorities of specialized facilities focus on stabilizing the patient, preventing infection, and optimizing functional recovery. Research on burns has generated sustained interest over the past few decades, and several important advancements have resulted in more effective patient stabilization and decreased mortality, especially among young patients and those with burns of intermediate extent. However, for the intensivist, challenges often exist that complicate patient support and stabilization. Furthermore, burn wounds are complex and can present unique difficulties that require late intervention or life-long rehabilitation. In addition to improvements in patient stabilization and care, research in burn wound care has yielded advancements that will continue to improve functional recovery. This article reviews recent advancements in the care of burn patients with a focus on the pathophysiology and treatment of burn wounds.
\end{abstract}

\section{Introduction}

Acute thermal injuries requiring medical treatment affect nearly half a million Americans each year, with approximately 40,000 hospitalizations and 3,400 deaths annually [1]. The survival rate for admitted burn patients has improved consistently over the past four decades [2] and is currently a favorable $97 \%$ for patients admitted to burn centers [3]. This can be largely attributed to national decreases in burn size, improvements in burn critical care, and advancements in burn wound care and treatment that have been driven by research, as reflected in the dramatic increase in burn publications over the last several decades

\footnotetext{
* Correspondence: p.rowan.vol@mail.mil

'United States Army Institute for Surgical Research, 3698 Chambers Pass, Fort Sam Houston, TX 78234, USA

Full list of author information is available at the end of the article
}

$[4,5]$. Since the first International Congress on Research in Burns over 50 years ago, progress has been made in a host of areas, and vital improvements in early resuscitation, infection management, wound excision and coverage, and fluid management have helped in the fight against burn mortality [6, 7]. This review presents an update on the care of burn patients, with special emphasis on the mechanisms underlying burn wound healing and recent advancements in burn wound care.

\section{Pathophysiology of burn wounds}

Thermal burns from dry sources (fire or flame) and wet sources (scalds) account for approximately $80 \%$ of all reported burns [8] and can be classified based on the depth of burn $[9,10]$. In addition to local injury at the site of burn, severe thermal injury over a large area of the skin, roughly $20 \%$ total body surface area (TBSA) or greater, results in acute systemic responses collectively known as burn shock [11]. Burn shock is characterized by increased capillary permeability, increased hydrostatic pressure across the microvasculature, protein and fluid movement from the intravascular space into the interstitial space, increased systemic vascular resistance, reduced cardiac output, and hypovolemia requiring fluid resuscitation [12]. The edema that forms in the interstitial space forms rapidly in the first $8 \mathrm{~h}$ following burn injury, and continues to form more slowly for at least $18 \mathrm{~h}$ [13]. Volume requirements for resuscitation can be estimated by the total burn size and the patient's weight (or body surface area). Additional factors influencing these needs include the presence or absence of inhalation injury, the extent of full-thickness burns, and the time since injury [12]. The actual fluid infusion rate is then titrated hourly, based on the adequacy of physiological responses, such as the urine output [14].

Following successful resuscitation, patients with larger burns then enter a more prolonged period of hypermetabolism, chronic inflammation, and lean body mass wasting, all of which may impair wound healing [15]. 
Additionally, an increased susceptibility to infection due to altered immune status may lead to sepsis, further exacerbating systemic inflammation [16]. Sustained hypermetabolism and inflammation impair wound healing through delayed re-epithelialization $[17,18]$. The extent of inflammation and hypermetabolism is related to the extent [19] and depth of burn, as deeper burns show higher levels of circulating cytokines [20] and a greater hypermetabolic response [21]. Similarly, the extent of burn is an efficient predictor of hospital length of stay $[19,22]$ and mortality $[19,23]$.

According to one model, the burn wound can be divided into three zones based on the severity of tissue destruction and alterations in blood flow [10, 24-26]. The central part of the wound, known as the zone of coagulation, is exposed to the greatest amount of heat and suffers the most damage. Proteins denature above $41{ }^{\circ} \mathrm{C}$ $\left(106^{\circ} \mathrm{F}\right)$, so excessive heat at the site of injury results in extensive protein denaturation, degradation, and coagulation, leading to tissue necrosis. Around the central zone of coagulation is the zone of stasis, or zone of ischemia, which is characterized by decreased perfusion and potentially salvageable tissue [10]. In this zone, hypoxia and ischemia can lead to tissue necrosis within $48 \mathrm{~h}$ of injury in the absence of intervention [27]. The mechanisms underlying apoptosis and necrosis in the ischemic zone remain poorly understood, but appear to involve immediate autophagy within the first $24 \mathrm{~h}$ following injury and delayed-onset apoptosis around 24 to $48 \mathrm{~h}$ postburn [27]. Other studies have shown apoptosis to be active as early as 30 min postburn [28] depending on the intensity of the burn injury [29]. Oxidative stress may play a role in the development of necrosis, as preclinical studies have demonstrated promising reductions in necrosis with systemic antioxidant administration [30]. At the outermost regions of the burn wound is the zone of hyperemia that receives increased blood flow via inflammatory vasodilation and will likely recover, barring infection or other injury [25].

Although burns are different from other wounds in some respects, such as the degree of systemic inflammation [31], healing of all wounds is a dynamic process with overlapping phases [32] (Table 1). The initial inflammatory phase brings neutrophils and monocytes to the site of injury via localized vasodilation and fluid extravasation, thereby initiating an immune response that is later sustained by the recruitment of macrophages by chemokines [31]. The inflammatory phase serves not only to prevent infection during healing, but also to degrade necrotic tissue and activate signals required for wound repair [33]. Following, and overlapping with the inflammatory response, the proliferative phase is characterized by keratinocyte and fibroblast activation by cytokines and growth factors [34]. In this phase, keratinocytes
Table 1 Phases of wound healing

\begin{tabular}{lll}
\hline Phase & Characteristics & Key players \\
\hline Inflammatory & Vasodilation & Neutrophils \\
& Fluid extravasation & Monocytes \\
& Edema & Macrophages \\
Proliferative & Wound closure & Keratinocytes \\
& Revascularization & Fibroblasts \\
Remodeling & Wound maturation & Collagen \\
& Scarring & Elastin \\
& & Fibroblasts/myofibroblasts \\
\hline
\end{tabular}

migrate over the wound to assist in closure and restoration of a vascular network, which is a vital step in the wound healing process [35]. This network of communication between stromal, endothelial, and immune cells determines the course of healing, including closure and revascularization.

Overlapping with the proliferative phase, the final phase of healing involves remodeling the wound [36]. During the remodeling phase, the wound scar matures [31] as collagen and elastin are deposited and continuously reformed as fibroblasts become myofibroblasts [37]. Myofibroblasts adopt a contractile phenotype, and thus are involved in wound contracture [38]. The conversion from fibroblasts to myofibroblasts controls a delicate balance between contraction and re-epithelialization that, in part, determines the pliability of the repaired wound [39]. In addition to fibroblast conversion, apoptosis of keratinocytes and inflammatory cells are key steps in the termination of wound healing and the overall final appearance of the wound [40].

\section{Optimization of burn wound healing Inflammation}

Inflammation is vital to successful burn wound healing, and inflammatory mediators (cytokines, kinins, lipids, and so forth) provide immune signals to recruit leukocytes and macrophages that initiate the proliferative phase [37]. Wound re-epithelialization, or closure, in the proliferative phase via keratinocyte and fibroblast activation, or migration from dedifferentiated hair follicles and other epidermal analogs $[41,42]$, is mediated by cytokines recruited in the inflammatory phase. While this indicates that inflammation is essential for wound healing, aberrant inflammatory pathways have also been linked to hypertrophic scarring, and anti-inflammatory treatments could potentially aggravate symptoms and delay wound healing $[40,43,44]$.

Significant edema that is initiated by several factors including vasodilation, extravascular osmotic activity, and increased microvascular permeability often accompanies inflammation [45]. Excessive or prolonged edema and 
inflammation exacerbate pain and impair wound healing $[17,18]$. Interestingly, studies suggest that in the absence of infection, inflammation might not be required for tissue repair [46]. Since inflammation can have both beneficial and detrimental effects on burn wound healing, the clinical challenge becomes management, applying therapeutic intervention only when inflammation and edema become excessive.

Treatment of inflammation in large burns is difficult, as recently discussed in detail elsewhere [16]. Traditional anti-inflammatory treatments that focus on the inhibition of prostaglandin synthesis, such as nonsteroidal anti-inflammatory drugs or glucocorticoids, impair wound healing [47]. However, steroid administration has been shown to reduce inflammation, pain, and length of hospital stay in burn patients in several small studies [48, 49]. Early excision and grafting has become the gold standard for treatment of full and deep partial thickness burns $[50,51]$, in part because early excision helps reduce the risk of infection and scarring [52-54]. The timing of debridement coincides with the inflammatory phase of healing, as the burn eschar removed during excision is an inflammatory nidus and a rich pabulum for bacterial proliferation.

Nontraditional anti-inflammatory treatments, such as opioids, have gained considerable attention but have yet to translate promising preclinical results into clinical practice for wound healing. While the majority of animal studies have demonstrated consistent anti-inflammatory effects of opioids on peripheral neurons [55], clinical studies have shown little to no effect on inflammation [56]. Furthermore, topical morphine delayed the early inflammatory phase and accelerated the later proliferative phase $[57,58]$, which is supported by in vitro studies showing opioid stimulation of keratinocyte migration [59]. Large-scale clinical trials evaluating opioid efficacy on wound healing have not yet been conducted [60].

\section{Infection}

The skin functions as a barrier to the external environment to maintain fluid homeostasis and body temperature, while providing sensory information along with metabolic and immunological support. Damage to this barrier following a burn disrupts the innate immune system and increases susceptibility to bacterial infection [61]. Burn wound infection was defined in a rat model with Pseudomonas aeruginosa [62, 63], in which the following progression was observed: burn wound colonization; invasion into subjacent tissue within 5 days; destruction of granulation tissue; visceral hematogenous lesions; and leukopenia, hypothermia, and death. Burn patients are at high risk for infection [64], especially drugresistant infection [65], which often results in significantly longer hospital stays, delayed wound healing, higher costs, and higher mortality [66]. Infection can lead to the development of a pronounced immune response, accompanied by sepsis or septic shock, which results in hypotension and impaired perfusion of end organs, including the skin all processes that delay wound healing. Furthermore, the leading causes of death following a severe burn are sepsis and multiorgan failure [67-69], so prevention and management of infection is a primary concern in the treatment of burn patients. Early and accurate diagnosis of infection is difficult: C-reactive protein and the white blood cell count are most often used, since the diagnostic power of procalcitonin is questionable in burns [70]. Consensus definitions of sepsis and infection have recently been proposed that are more relevant to the burn population and are often used clinically but still require validation [71].

The management of burn wound infections has been extensively reviewed elsewhere [61, 64-66, 72-77]. Since the adoption of topical antibiotics, such as mafenide in the 1960s and silver sulfadiazine in the 1970s, and of early excision and grafting in the 1970s and thereafter, systemic infections and mortality have consistently decreased [68, 72, 78]. However, Gram-positive and Gramnegative bacterial infections still remain one of the most common causes of mortality following burn injury [73]. Bacterial cultures can aid in the selection of an appropriate antibiotic, especially in cases of bacterial drug resistance, but altered pharmacokinetic parameters in burn patients must be considered and dosing should be adjusted accordingly to maximize antibiotic efficacy [79]. Importantly, effective topical antimicrobials do not exist for invasive fungal infections, and fungal wound infections are associated with greater mortality rates in large burns (>30 \% TBSA) [80]. Owing to high lethality, suspicion of an invasive burn wound infection mandates rapid diagnosis, often by histopathology, and excision or reexcision of the wound.

\section{Nutrition}

Sustained hypermetabolism, hormone elevations, and muscle wasting following severe burn injury all contribute to the clinical outcome, with magnitude and duration that are unique to burns $[81,82]$. Accordingly, reducing the impact of a hypermetabolic state and providing adequate nutrition are key factors that affect burn wound healing and recovery [83], as has been reviewed elsewhere [84]. There is a difficult balance between the additional caloric needs to meet the demand from hypermetabolism and the consequences of nutrient overconsumption. Nutritional support following a burn injury is a complex issue. For example, early excision and aggressive feeding in children does not diminish energy expenditure but is associated with decreased muscle protein catabolism, a decreased rate of burn sepsis, and significantly lower bacterial counts from excised tissue 
[85]. In adults, early nutritional support is correlated with shorter stays, accelerated wound healing, and decreased risk of infection [86].

Several nutritional factors must be considered. For example, excess carbohydrate consumption may lead to hyperglycemia [87] that can exacerbate systemic inflammation and muscle degradation [88, 89]. Furthermore, excess fat consumption may exaggerate the immunosuppressed state [90]; and since major burn injuries may also result in immunosuppression [91], this exaggeration may increase the risk for infection and sepsis. Carbohydrate and fat intake must therefore be closely monitored in burn patients. Guidelines for nutritional support of burn patients vary, but consensus recommendations have been given by the American Burn Association and the American Society for Parenteral and Enteral Nutrition for carbohydrates, proteins, and fats [84].

In addition to support with amino acids and vitamins [84], administration of insulin has been shown to decrease healing time by reducing protein catabolism and increasing skeletal muscle protein synthesis [92-96]. More research is needed to optimize insulin delivery, as many recombinant growth factors, such as epidermal growth factor and transforming growth factor, are often cost prohibitive [93]. Other anabolic agents, such as oxandrolone, have been shown to increase lean body mass recovery, decrease length of stay, and improve overall outcomes, including wound healing [97-100]. Additionally, while conventional theory suggests that hemoglobin levels must be maintained above $10 \mathrm{~g} / \mathrm{dl}$ to promote wound healing [101], preliminary evidence suggests that mild to moderate anemia has no effect on graft success if perfusion is maintained with proper circulatory volume [102]. The results of a multicenter, randomized, controlled trial (ClinicalTrials.gov NCT01079247) comparing blood transfusion with lower volumes (target hemoglobin of 7 to $8 \mathrm{~g} / \mathrm{dl}$ ) and conventional volumes (target hemoglobin $>10 \mathrm{~g} / \mathrm{dl}$ ) for a large cohort of patients are expected soon and will allow for more definitive clinical guidelines on blood transfusion volumes.

\section{Resuscitation}

Severe thermal injuries over a large area of the skin $(>20 \%$ TBSA) require fluid resuscitation for stabilization. Although volume guidelines and fluid compositions vary widely between centers, the goal of fluid resuscitation is to maintain organ perfusion with the least amount of fluid necessary [12]. Common traditional resuscitation formulas, such as the modified Brooke, and Parkland formulas, employ crystalloids such as lactated Ringer's that contain sodium, chloride, calcium, potassium, and lactate. During large-volume resuscitations, the addition of colloids (for example, albumin, fresh frozen plasma) as adjuncts has been successful in reducing the total volume [12]. Despite extensive research into resuscitation fluid compositions and volumes, little is known about the effect of resuscitation on wound healing. A recent meta-analysis showed a positive association between the number of grafting procedures and hypernatremia, suggesting that high serum sodium levels may inhibit graft take [103]. Additionally, we have recently shown that the rate of wound closure (healing rate) is significantly faster in patients who received lower 24-h fluid resuscitation volumes [104]. More work is needed to evaluate the effect of resuscitation on wound healing trajectories before clinical recommendations for preferred fluid compositions and volumes can be made.

\section{Wound coverage and grafting}

Early excision and grafting has been the standard of care for decades. Most studies have shown that excision within 24 to $48 \mathrm{~h}$ after injury is associated with decreased blood loss, infection, length of hospital stay and mortality, and increased graft take [105-108], although mortality reductions may only occur in patients without inhalation injury [109]. Since one of the main challenges in treating acute thermal injuries is preventing infection, excising the eschar and covering the wound as early as possible are critical. The standard for rapid and permanent closure of full-thickness burns is a split-thickness skin graft from an uninjured donor site on the same patient (autograft). Such grafting provides sufficient coverage without risk of rejection, although meta-analyses have yet to determine the failure rate of split-thickness skin grafts in burn patients. Split-thickness skin grafts can be meshed with variable expansion ratios to increase the coverage area, but concerns remain over the effect that meshing has on range of motion [110] and the graft site healing rate. On the other hand, donor sites are painful and impose their own wound-healing burden on the patient [111]. Various dressings have been used to cover donor sites during healing, with variable results [112].

Patients with more extensive burns often require temporary coverage with an allograft, xenograft, skin substitute, or dermal analog due to insufficient or unavailable donor sites. Allografts, or tissue taken from a living or deceased human donor, and xenografts, taken from a different species, promote re-epithelialization and prepare the wound bed for autograft, increasing the healing rate when compared with traditional dressings [113]. A recent meta-analysis suggested that since allografts and xenografts appear to be equally effective, xenografts may be a superior choice for their increased safety and reduced price [114]. However, caution should be exercised in drawing broad conclusions from this meta-analysis because the cited studies lack standardization and critical details such as depth and size of burn, and many studies cited were merely anecdotal. A cadaver allograft 
is thus widely considered the best material for temporary closure of excised wounds in patients with extensive, life-threatening burns and inadequate donor sites. The cadaver allograft is also the preferred material for protection of widely meshed autografts (3:1 or higher meshing ratios) during healing. In the latter setting, the allograft is applied over the meshed autograft in the manner of a sandwich.

A variety of different skin substitutes and dermal analogs exist [115-119] (Table 2) that can be broadly divided into those which replace the epidermis or replace the dermis $[120,121]$. Epidermal substitutes are normally only a few cell layers thick and lack normal dermal components [122, 123]. Commercially available dermal substitutes include acellular matrices, commonly from human - for example, Alloderm (LifeCell, Bridgewater, NJ, USA) or GraftJacket (KCI, San Antonio, TX, USA) - or other sources (for example, Integra; Integra LifeSciences, Plainsboro, NJ, USA). Biobrane (Smith \& Nephew, London, UK) is a semisynthetic, bilaminar material consisting of a nylon-mesh dermal analog (bonded with porcine collagen) and a silicone epidermal analog. Biobrane is used for temporary closure of superficial burns and donor sites [124, 125]. Products currently under development integrate the concept of dermal scaffolds that actively promote revascularization by incorporating stem cells and growth factors to recreate a favorable cellular microenvironment [126, 127].

Numerous options exist for dressings [128, 129]. The selection of an appropriate dressing depends on several factors, including depth of burn, condition of the wound bed, wound location, desired moisture retention and drainage, required frequency of dressing changes, and cost. While many factors must be considered in dressing selection, the goals in selecting the most appropriate dressing should include providing protection from contamination (bacterial or otherwise) and from physical damage, allowing gas exchange and moisture retention, and providing comfort to enhance functional recovery. The traditional approach to burn wound care developed at the US Army Burn Center includes alternation of mafenide acetate cream in the morning and silver sulfadiazine cream in the evening, with gauze dressings used over the creams. More recently, silver-impregnated and other dressings have been introduced. Major classes of dressings include: alginate, for example Aquacel (ConvaTec, Bridgewater, NJ, USA), Comfeel (Coloplast, Minneapolis, MN, USA), or Sorbsan (Mylan, Morgantown, WV, USA); antimicrobial, for example Acticoat (Smith \& Nephew, London, UK) or Silverlon (Argentum, Geneva, IL, USA); collagen, for example Fibracol (Johnson \& Johnson, New Brunswick, NJ) or Puracol (Medline, Mundelein, IL, USA); hydrocolloid, for example Duoderm (ConvaTec, Bridgewater, NJ, USA), Granuflex (ConvaTec, Bridgewater, NJ, USA), or Tegaderm (3M, Maplewood, MN, USA); hydrogel, for example Dermagel (Maximilian Zenho \& Co, Brussels, Belgium), SilvaSorb (Medline, Mundelein, IL, USA), or Skintegrity (Medline, Mundelein, IL, USA); and polyurethane foam, for example Allevyn (Smith \& Nephew, London, UK) or Lyofoa (Molnycke, Gothenburg, Sweden). Notably, many of these dressings exhibit antimicrobial properties through silver impregnation, but recent studies suggest silver may delay wound healing and should not be routinely used on uninfected donor skin $[130,131]$ even though silver dressings may reduce wound pain [132]. In patients with extensive or deep burns, antimicrobial efficacy should be the first priority in burn wound care.

Alternatively, cell-based techniques for more permanent coverage have made progress. Research on cultured

Table 2 Skin substitutes and coverage options

\begin{tabular}{|c|c|c|c|}
\hline Product name & Classification & Characteristics & Availability (company) \\
\hline EpiDex & Autologous & Keratinocyte-based & No (Modex, Lausanne, Switzerland) \\
\hline \multirow[t]{2}{*}{ Alloderm } & \multirow[t]{2}{*}{ Acellular } & Human origin & \multirow[t]{2}{*}{ Yes (LifeCell, Bridgewater, NJ, USA) } \\
\hline & & Dermal matrix & \\
\hline \multirow[t]{2}{*}{ GraftJacket } & \multirow[t]{2}{*}{ Acellular } & Human origin & \multirow[t]{2}{*}{ Yes (KCl, San Antonio, TX, USA) } \\
\hline & & Tissue scaffold & \\
\hline \multirow[t]{2}{*}{ Integra } & \multirow[t]{2}{*}{ Acellular } & Bovine/shark origin & \multirow[t]{2}{*}{ Yes (Integra, Plainsboro, NJ, USA) } \\
\hline & & Bilayer matrix & \\
\hline Biobrane & Acellular & Biocomposite dressing, nylon fibers in silicone with collagen & Yes (Smith \& Nephew, London, UK) \\
\hline Dermagraft & Cellular & $\begin{array}{l}\text { Bioabsorbable polyglactin mesh scaffold with human fibroblasts } \\
\text { (neonatal origin) }\end{array}$ & Yes (Organogenesis, Canton, MA, USA) \\
\hline Epicel & Cellular & Keratinocyte-based cultured epidermal autograft & Yes (Genzyme, Cambridge, MA, USA) \\
\hline \multirow[t]{2}{*}{ Recell } & \multirow[t]{2}{*}{ Cellular } & $\begin{array}{l}\text { Autologous cell suspension of keratinocytes, fibroblasts, } \\
\text { Langerhans cells and melanocytes }\end{array}$ & \multirow[t]{2}{*}{ Yes (Avita, Northridge, CA, USA) } \\
\hline & & Sprayable after culture & \\
\hline
\end{tabular}


epithelial cells has made advancements, especially with respect to culture time. Culture-based options, such as Epicel (Genzyme, Cambridge, MA, USA), use a small biopsy of the patient's skin to provide keratinocytes, which are expanded over 2 to 3 weeks (for Epicel, in the presence of proliferation-arrested murine fibroblasts) into a confluent epidermal autograft. Other options, such as ReCell (Avita, Northridge, CA, USA), take a small biopsy of the patient's skin and prepare a mixture of keratinocytes, melanocytes, and stem cells in a liquid formulation for spraying onto the excised burn wound during the same operation [133-135]. These techniques may reduce the amount of donor skin needed for treatment of large burns, significantly reducing the healing time of both the donor and the burn sites, and increasing overall graft success and scar quality [136]. More work is needed on cell-based coverage options before widespread implementation can be recommended.

\section{Keratinocytes and stem cells}

As mentioned previously, keratinocytes play a vital role in wound closure. Cytokine activation causes keratinocyte migration in the proliferative phase, leading to closure and restoration of a vascular network [35]. Keratinocytes can also be activated by mu opioid receptor agonists [59] but the role of these agonists on inflammation and wound closure remains unclear $[57,58]$. Despite positive studies with EpiDex (Modex, Lausanne, Switzerland) - an engineered, fully differentiated autologous skin substitute derived from keratinocytes showing efficacy comparable with split-thickness skin grafts in wound closure and healing [137] - results have yet to translate into clinically viable options. Studies evaluating expansion of keratinocytes on human fibroblasts following trypsin extraction [138], and using engineered skin with keratinocytes on a fibrin matrix [139], have demonstrated improvements in wound healing. Retrospective analyses on autologous keratinocytes showed that cultured allogeneic or autologous keratinocytes may accelerate wound healing $[140,141]$. Taken together, the future impact of keratinocyte-mediated cell coverage options is promising, but more research is needed [134]. Additionally, keratinocyte-based treatments should be pursued carefully, as overactivation of keratinocytes can contribute to the development of hypertrophic scarring [43, 142].

The use of adult stem cells, including bone marrow stem cells, hair follicle stem cells, and adipose stem cells, in acute burn care is an exciting topic [143]. Addition of bone marrow stem cells to nonhealing chronic wounds leads to engraftment of cells and enhanced wound healing [144, 145]. Moreover, studies have reported that bone marrow stem cells can transdifferentiate towards multiple skin cell types [146]. Mechanisms of action of bone marrow stem cells in burns are not fully elucidated, but modulation of inflammation has occurred after radiation burns in humans [147]. Similarly, adipose stem cells accelerate re-epithelialization by paracrine activation of host cells via growth factor secretion [148, 149]. Also, hair follicle stem cells are capable of generating a stratified epidermis on human burn wounds [150]. Additionally, the possibility of generating a cellular skin equivalent is being explored. Hair follicle stem cells have been incorporated into products, such as Integra, to investigate wound healing [151]. A cultured skin substitute using adipose stem cells and keratinocytes has been developed that produces epidermal, dermal, and hypodermal stratification [152]. Moreover, human adipose stem cells that would normally be discarded have recently been isolated from debrided burn eschar tissue [153] and used to generate a tri-layered, vascularized construct [154]. Promising data with nonembryonic stems cells such as these have stimulated interest into future applications and development, and undoubtedly further investigations will produce exciting results.

\section{Other considerations and future directions Monitoring and predicting wound healing}

No new skin-based technology can substitute for careful attention by the burn team to the progress (or lack thereof) of wound healing. The WoundFlow computer software program was developed as an enhancement over the traditional paper Lund-Browder diagram to more accurately quantify and track burn injuries over time [104, 155]. WoundFlow is an electronic mapping program that calculates burn size and tracks wound healing $[104,155]$. The ability to accurately track burn wound healing over time will support both clinical care and future studies that compare healing rates and outcomes following different treatments. Notably, this study demonstrated that delayed wound healing was associated with a significantly higher risk of mortality [104, 155].

The ability to predict whether a burn wound will spontaneously heal or not would greatly improve patient care. Furthermore, the ability to uniquely tailor treatment to each individual patient would improve patient outcomes and decrease the time to functional recovery, reducing the overall cost of care. Biomarkers may provide a means to allow for tailored treatments and to give insight into wound healing mechanisms [156-161]. Significant efforts in the search for predictive biomarkers for wound failure have determined that serum cytokines, such as interleukin-3 and $12 \mathrm{p} 70$, and serum procalcitonin are independently associated with wound failure [161]. Additional candidates have been identified [158-160] but further work is needed to model complex, temporal serum cytokine profiles into an effective predictor for wound healing. In addition to evaluating serum cytokine profiles, candidate biomarkers have been identified in 
wound effluent [161], which may be a better medium for predicting local wound healing than cytokines in the circulation [162]. Wound exudate has been shown to contain elevated levels of immunosuppressive and proinflammatory cytokines, such as interleukin-1 $\beta$, interleukin-2, interleukin-6, and tumor necrosis factor alpha [163]. In fact, dipeptidyl peptidase IV and aminopeptidase have been identified in burn wound exudate with a significantly different ratio from that found in plasma [164]. Other work on local wound biomarkers using biopsies has shown that a host of proteins are upregulated during wound healing [165]. More work is needed to establish a biomarker profile that can accurately predict wound healing and to identify potential novel areas for therapeutic intervention.

In addition to examining burn wounds directly, and the wound exudate, another potential method for examining the ability of burn wounds to heal is non-invasive imaging [166]. To this end, a number of non-invasive imaging techniques have been investigated for their use in determining burn depth. Such techniques include terahertz imaging, spatial-frequency-domain imaging, nearinfrared spectroscopic imaging, and reflectance-mode confocal microscopy, among others [167-172]. While many of these techniques have not yet been refined sufficiently for clinical application, the most successful research efforts into imaging techniques for burn wounds examine blood flow, such as laser Doppler imaging and indocyanine green angiography [173]. Laser Doppler imaging provides the most evidence for accurately assessing burn severity [174], but it has been shown that laser Doppler imaging is only superior to visual assessment $48 \mathrm{~h}$ after thermal injury [175]. Additional studies are needed to fully explore the potential for incorporation of non-invasive imaging modalities into the routine treatment of burn wounds.

\section{Obese patients}

As the obese population continues to grow [176], new treatment approaches will be required. Obese burn patients present with a variety of unique characteristics that include: increased rates of diabetes, hypertension, cardiac disease, and pulmonary disease; altered pharmacokinetics and pharmacodynamics; and altered immune responses [177]. Even the commonly used Lund-Browder chart for estimation of TBSA is problematic for obese patients because it fails to account for altered body-mass distribution in these patients [178]. Hence, analysis of group differences and controlled clinical studies in unique patient populations are needed [179].

\section{Older patients}

Census predictions suggest that the older population will double in the next 20 years. Since older people are at increased risk for burn injury, an increasing number of burn injuries among the older population should be expected. A recent review delineated the unique burn pathophysiology, comorbidities, and treatment strategies for the older population [180]. Detailing all of the unique considerations for the older burn population is outside the scope of this review, but several key points are noteworthy. Most burns among older people occur at home, especially in the kitchen and bathroom, due to diminished alertness, slower reaction time, and reduced mobility [181]. Reductions in metabolic rate and skin thickness with age result in more severe burns, and more extensive full-thickness burns are associated with increased mortality [182]. Comorbidities such as diabetes and cardiovascular disease complicate treatment, and may exacerbate the postburn hypermetabolic response [183]. Several formulas for predicting the survival of older patients, such as the Baux score [184], have received wide acceptance and can help guide clinicians in patient treatment. Unique treatment considerations for older patients should include attentive resuscitation to reduce the risk of volume overload, judicious ventilator support, careful analgesic administration, prudently timed excision and grafting, and extended rehabilitation for functional recovery [180]. The older population presents a unique challenge to the burn clinician, and the treatment of patients must be carefully considered on a case-by-case basis.

\section{Future directions}

Adult burn patients with increased markers of inflammatory stress exhibit reduced serum levels of vitamin A despite normal markers of oxidative stress [185-187]. Additionally, limited preclinical studies show that polyprenoic acid and retinol can facilitate wound healing [188], and that retinoids are efficacious on a variety of other skin conditions [189]. Moreover, early clinical studies have shown that retinoid treatment effectively increases scar elasticity $[190,191]$. Taken together, these

\section{Table 3 Recommendations for the intensivist}

Accurate measurement of burn size using a Lund-Browder chart

Carefully titrated fluid resuscitation, to balance risks of edema formation with those of ongoing hypoperfusion

Early initiation of effective topical antimicrobial therapy (mafenide acetate or silver-based creams/dressings)

Daily inspection of the wounds by a qualified surgeon or wound care expert

Early excision and grafting of all full thickness and deep partial thickness burns

Aggressive treatment of infected wounds (resuscitate, broad-spectrum topical and systemic antimicrobials, excision, or re-excision)

Rehabilitation in the ICU to minimize the functional consequences of prolonged immobilization and contracture formation 
data highlight the need for studies evaluating retinoids on burn wound healing outcomes.

Pirfenidone was originally developed as an antihelminthic and antipyretic agent, but recent work has demonstrated that it also has anti-inflammatory, antioxidative, and antiproliferative effects [192]. In particular, the antifibrotic properties of pirfenidone attenuate fibroblast proliferation and collagen deposition in vitro and in preclinical models [192]. Pirfenidone is approved for the treatment of idiopathic pulmonary fibrosis in Europe, Japan, and the USA. The antifibrotic actions of pirfenidone and other data suggest that pirfenidone could modulate the tissue response to injury at multiple stages of wound repair to improve scarring and function as an adjuvant for abnormal wound healing processes. Preclinical investigations are currently underway in rabbits $[193,194]$ and rats [195], but controlled clinical studies are needed to evaluate the safety and efficacy of pirfenidone on abnormal wound healing.

The treatment of burn wounds with hyperbaric oxygen was first investigated in the mid-1960s and garnered some attention in the decades following, but controversy remains over potential risks and costs [196, 197]. Recent work in rat models has shown that hyperbaric oxygen reduces healing time and improves scar appearance of burn injuries [198]. Advancements in hyperbaric chambers have reduced the overall cost associated with treatment, and controlled clinical trials in humans are beginning to produce data supporting the conclusion that hyperbaric oxygen is safe and effective for improving burn wound healing [199-201]. However, more data are needed before broad conclusions can be made about the overall utility of hyperbaric oxygen for treating burns.

Future research on burn patient care will focus on a variety of areas [202]. Considering a current survival rate of over $97 \%$ for burn patients [3], major advancements from the past several decades have improved patient care such that significant future improvements in patient survival rate will be more difficult. However, improvements are still needed in individualized care, namely prediction of patient outcomes and the ability to tailor treatment to optimize functional recovery. Improvements are also needed to accelerate wound closure and healing and to improve psychological care to promote successful reintegration. Research in inflammation, infection, stem cells, grafting, biomarkers, inflammation control, and rehabilitation will continue to improve individualized care and create new treatment options.

\section{Conclusion}

The various clinical challenges in treating acute thermal injuries include balancing the many factors that affect wound healing to reduce the length of stay (and associated cost of treatment), the risk of infection, the time to wound closure, and the overall time to functional recovery. The treatment of burn wounds has evolved over several decades through clinical and preclinical research. Significant advancements have been made in patient care, including tracking wound healing, developing novel graft and coverage options, controlling inflammation, optimizing dietary needs, and testing unique pharmacological interventions. As a result of these efforts, patient survival has improved along with a concomitant decrease in the length of stay, which in turn results in a decreased cost to the patient and the medical providers. A summary of selected clinical recommendations is provided (Table 3) to aid the intensivist, but it is important to remember that burn patients present unique challenges based on multiple variables (for example, age, TBSA, comorbidities) and treatment decisions must be tailored to each patient's needs. Current and future research will continue to identify novel targets and treatment paradigms to further improve burn wound care.

\section{Abbreviation}

TBSA: Total body surface area.

\section{Competing interests}

The authors declare that they have no competing interests.

\section{Authors' contributions}

MPR and KKC outlined the paper. MPR wrote all drafts of the manuscript, with primary editing and revision support from LCC. All authors contributed information for the manuscript, participated in its revision, and approved the final version for publication.

\section{Acknowledgements}

The authors would like to thank the staff of the Clinical Trials task area at the US Army Institute of Surgical Research for administrative support. The authors would also like to thank Dr Harold Klemcke for critical review of this manuscript. This work was supported in part by an appointment (MPR) to the Postgraduate Research Participation Program and an appointment (LCC) to the Knowledge Preservation Program at the US Army Institute of Surgical Research administered by the Oak Ridge Institute for Science and Education through an interagency agreement between the US Department of Energy and US Army Medical Research and Materiel Command.

The opinions or assertions contained herein are the private views of the authors and are not to be construed as official or as reflecting the views of the Department of the Army or the Department of Defense.

\section{Author details}

'United States Army Institute for Surgical Research, 3698 Chambers Pass, Fort Sam Houston, TX 78234, USA. ${ }^{2}$ Uniformed Services University of the Health Sciences, 4301 Jones Bridge Rd, Bethesda, MD 20814, USA. ${ }^{3}$ Brooke Army Medical Center, 3551 Roger Brook Dr, Fort Sam Houston, TX 78234, USA.

Published online: 12 June 2015

\section{References}

1. Gibran NS, Wiechman S, Meyer W, Edelman L, Fauerbach J, Gibbons L, et al. American Burn Association consensus statements. J Burn Care Res. 2013:34:361-5

2. Mann R, Heimbach D. Prognosis and treatment of burns. West J Med. 1996;165:215-20.

3. American Burn Association. Burn incidence and treatment in the United States: 2013 fact sheet. 2013. http://www.ameriburn.org/resources_ factsheet.php. Accessed 12 May 2015. 
4. Sen S, Palmieri T, Greenhalgh D. Review of burn research for the year 2013 J Burn Care Res. 2014;35:362-8.

5. Wolf SE, Arnoldo BD. The year in burns 2011. Burns. 2012;38:1096-108.

6. Burd A. Research in burns - present and future. Indian J Plast Surg. 2010;43:S11-4.

7. Thomas SJ, Kramer GC, Herndon DN. Burns: military options and tactical solutions. J Trauma. 2003;54:S207-18.

8. American Burn Association. National Burn Repository 2014. 2014. http://www.ameriburn.org/2014NBRAnnualReport.pdf. Accessed 12 May 2015

9. Kagan RJ, Peck MD, Ahrenholz DH, Hickerson WL, Holmes J, Korentager R, et al. Surgical management of the burn wound and use of skin substitutes: an expert panel white paper. J Burn Care Res. 2013;34:e60-79.

10. Nisanci M, Eski M, Sahin I, Ilgan S, Isik S. Saving the zone of stasis in burns with activated protein C: an experimental study in rats. Burns. 2010;36:397-402.

11. Robins EV. Burn shock. Crit Care Nurs Clin North Am. 1990;2:299-307.

12. Pham TN, Cancio LC, Gibran NS, American Burn Association. American Burn Association practice guidelines burn shock resuscitation. J Burn Care Res. 2008;29:257-66.

13. Shirani $K Z$, Vaughan $G M$, Mason Jr AD, Pruitt Jr BA. Update on current therapeutic approaches in burns. Shock. 1996:5:4-16.

14. Dries DJ. Management of burn injuries - recent developments in resuscitation, infection control and outcomes research. Scand J Trauma Resusc Emerg Med. 2009;17:14.

15. Porter C, Hurren NM, Herndon DN, Borsheim E. Whole body and skeletal muscle protein turnover in recovery from burns. Int J Burns Trauma. 2013;3:9-17.

16. Farina Jr JA, Rosique MJ, Rosique RG. Curbing inflammation in burn patients. Int J Inflamm. 2013:2013:715645.

17. Edgar DW, Fish JS, Gomez M, Wood FM. Local and systemic treatments for acute edema after burn injury: a systematic review of the literature. J Burn Care Res. 2011:32:334-47.

18. Sommer K, Sander AL, Albig M, Weber R, Henrich D, Frank J, et al. Delayed wound repair in sepsis is associated with reduced local pro-inflammatory cytokine expression. PLoS One. 2013;8, e73992.

19. Wilmore DW, Long JM, Mason Jr AD, Skreen RW, Pruitt Jr BA. Catecholamines: mediator of the hypermetabolic response to thermal injury. Ann Surg. 1974;180:653-69.

20. Sakallioglu AE, Basaran O, Karakayali H, Ozdemir BH, Yucel M, Arat Z, et al. Interactions of systemic immune response and local wound healing in different burn depths: an experimental study on rats. J Burn Care Res. 2006:27:357-66.

21. Pereira CT, Herndon DN. The pharmacologic modulation of the hypermetabolic response to burns. Adv Surg. 2005:39:245-61.

22. Hussain A, Dunn KW. Predicting length of stay in thermal burns: a systematic review of prognostic factors. Burns. 2013;39:1331-40.

23. Colohan SM. Predicting prognosis in thermal burns with associated inhalational injury: a systematic review of prognostic factors in adult burn victims. J Burn Care Res. 2010;31:529-39.

24. Jackson DM. The diagnosis of the depth of burning. Br J Surg. 1953:40:588-96

25. Hettiaratchy S, Dziewulski P. ABC of burns: pathophysiology and types of burns. BMJ. 2004;328:1427-9.

26. Kowalske KJ. Burn wound care. Phys Med Rehab Clin North Am. 2011:22:213-27.

27. Tan JQ, Zhang HH, Lei ZJ, Ren P, Deng C, Li XY, et al. The roles of autophagy and apoptosis in burn wound progression in rats. Burns. 2013:39:1551-6.

28. Singer AJ, McClain SA, Taira BR, Guerriero JL, Zong W. Apoptosis and necrosis in the ischemic zone adjacent to third degree burns. Acad Emerg Med. 2008;15:549-54.

29. Matylevitch NP, Schuschereba ST, Mata JR, Gilligan GR, Lawlor DF, Goodwin $\mathrm{CW}$, et al. Apoptosis and accidental cell death in cultured human keratinocytes after thermal injury. Am J Pathol. 1998;153:567-77.

30. Deniz M, Borman H, Seyhan T, Haberal M. An effective antioxidant drug on prevention of the necrosis of zone of stasis: $\mathrm{N}$-acetylcysteine. Burns. 2013;39:320-5

31. Tiwari VK. Burn wound: how it differs from other wounds? Indian J Plast Surg. 2012;45:364-73.

32. Gurtner GC, Werner S, Barrandon Y, Longaker MT. Wound repair and regeneration. Nature. 2008;453:314-21.
33. Reinke $\mathrm{JM}$, Sorg $\mathrm{H}$. Wound repair and regeneration. Eur Surg Res. 2012;49:35-43.

34. Werner S, Krieg T, Smola H. Keratinocyte-fibroblast interactions in wound healing. J Invest Dermatol. 2007;127:998-1008.

35. Pastar I, Stojadinovic O, Yin NC, Ramirez H, Nusbaum AG, Sawaya A, et al. Epithelialization in wound healing: a comprehensive review. Adv Wound Care. 2014;3:445-64.

36. Widgerow AD. Cellular/extracellular matrix cross-talk in scar evolution and control. Wound Repair Regen. 2011;19:117-33.

37. Singer AJ, Clark RA. Cutaneous wound healing. N Engl J Med. 1999:341:738-46.

38. Hinz B. Formation and function of the myofibroblast during tissue repair. J Invest Dermatol. 2007;127:526-37.

39. Snowden JM. Wound closure: an analysis of the relative contributions of contraction and epithelialization. J Surg Res. 1984;37:453-63.

40. Shih B, Garside E, McGrouther DA, Bayat A. Molecular dissection of abnormal wound healing processes resulting in keloid disease. Wound Repair Regen. 2010;18:139-53.

41. Claudinot S, Nicolas M, Oshima H, Rochat A, Barrandon Y. Long-term renewal of hair follicles from clonogenic multipotent stem cells. Proc Natl Acad Sci U S A. 2005;102:14677-82.

42. Ito M, Liu Y, Yang Z, Nguyen J, Liang F, Morris RJ, et al. Stem cells in the hair follicle bulge contribute to wound repair but not to homeostasis of the epidermis. Nat Med. 2005;11:1351-4

43. Curran TA, Ghahary A. Evidence of a role for fibrocyte and keratinocyte-like cells in the formation of hypertrophic scars. J Burn Care Res. 2013;34:227-31.

44. Tabas I, Glass CK. Anti-inflammatory therapy in chronic disease: challenges and opportunities. Science. 2013;339:166-72

45. Arturson $\mathrm{G}$. Forty years in burns research - the postburn inflammatory response. Burns. 2000;26:599-604.

46. Szpaderska AM, DiPietro LA. Inflammation in surgical wound healing: friend or foe? Surgery. 2005;137:571-3.

47. Franz MG, Steed DL, Robson MC. Optimizing healing of the acute wound by minimizing complications. Curr Probl Surg. 2007;44:691-763.

48. Stubhaug A, Romundstad L, Kaasa T, Breivik H. Methylprednisolone and ketorolac rapidly reduce hyperalgesia around a skin burn injury and increase pressure pain thresholds. Acta Anaesthesiol Scand. 2007;51:1138-46.

49. Huang G, Liang B, Liu G, Liu K, Ding Z. Low dose of glucocorticoid decreases the incidence of complications in severely burned patients by attenuating systemic inflammation. J Crit Care. 2015;30:e7-11.

50. Janzekovic Z. A new concept in the early excision and immediate grafting of burns. J Trauma. 1970;10:1103-8.

51. Orgill DP. Excision and skin grafting of thermal burns. N Engl J Med. 2009;360:893-901.

52. Barret JP, Herndon DN. Effects of burn wound excision on bacterial colonization and invasion. Plast Reconstruct Surg. 2003;111:744-50. discussion 751-2.

53. Cramer LM, McCormack CR, Carroll DB. Progressive partial excision and early graftin in lethal burns. Plast Reconstruct Surg Transplant Bull. 1962;30:595-9.

54. Engrav LH, Heimbach DM, Reus JL, Harnar TJ, Marvin JA. Early excision and grafting vs. nonoperative treatment of burns of indeterminant depth: a randomized prospective study. J Trauma. 1983;23:1001-4.

55. Stein C, Kuchler S. Non-analgesic effects of opioids: peripheral opioid effects on inflammation and wound healing. Curr Pharm Des. 2012;18:6053-69.

56. Brack A, Rittner HL, Stein C. Immunosuppressive effects of opioids - clinical relevance. J Neuroimmune Pharmacol. 2011;6:490-502.

57. Rook JM, Hasan W, McCarson KE. Morphine-induced early delays in wound closure: involvement of sensory neuropeptides and modification of neurokinin receptor expression. Biochem Pharmacol. 2009;77:1747-55.

58. Rook JM, McCarson KE. Delay of cutaneous wound closure by morphine via local blockade of peripheral tachykinin release. Biochem Pharmacol. 2007;74:752-7.

59. Bigliardi PL, Buchner S, Rufli T, Bigliardi-Qi M. Specific stimulation of migration of human keratinocytes by mu-opiate receptor agonists. J Recept Signal Transduct Res. 2002;22:191-9.

60. Stein C, Kuchler S. Targeting inflammation and wound healing by opioids. Trends Pharmacol Sci. 2013;34:303-12.

61. Church D, Elsayed S, Reid O, Winston B, Lindsay R. Burn wound infections. Clin Microbiol Rev. 2006;19:403-34.

62. Teplitz C, Davis D, Walker HL, Raulston GL, Mason Jr AD, Moncrief JA Pseudomonas burn wound sepsis. II Hematogenous infection at the 
junction of the burn wound and the unburned hypodermis. J Surg Res. 1964:4:217-22.

63. Teplitz C, Davis D, Mason Jr AD, Moncrief JA. Pseudomonas burn wound sepsis. I Pathogenesis of experimental pseudomonas burn wound sepsis. J Surg Res. 1964;4:200-16.

64. Coban YK. Infection control in severely burned patients. World I Crit Care Med. 2012;1:94-101.

65. Branski LK, Al-Mousawi A, Rivero H, Jeschke MG, Sanford AP, Herndon DN. Emerging infections in burns. Surg Infect. 2009;10:389-97.

66. Shupp JW, Pavlovich AR, Jeng JC, Pezzullo JC, Oetgen WJ, Jaskille AD, et al. Epidemiology of bloodstream infections in burn-injured patients: a review of the national burn repository. J Burn Care Res. 2010;31:521-8.

67. Bloemsma GC, Dokter J, Boxma H, Oen IM. Mortality and causes of death in a burn centre. Burns. 2008;34:1103-7.

68. Chipp E, Milner CS, Blackburn AV. Sepsis in burns: a review of current practice and future therapies. Ann Plastic Surg. 2010;65:228-36.

69. Williams FN, Herndon DN, Hawkins HK, Lee JO, Cox RA, Kulp GA, et al. The leading causes of death after burn injury in a single pediatric burn center. Crit Care. 2009;13:R183

70. Mann EA, Wood GL, Wade CE. Use of procalcitonin for the detection of sepsis in the critically ill burn patient: a systematic review of the literature. Burns. 2011;37:549-58.

71. Greenhalgh DG, Saffle JR, Holmes JH, Gamelli RL, Palmieri TL, Horton JW, et al. American Burn Association consensus conference to define sepsis and infection in burns. J Burn Care Res. 2007:28:776-90.

72. D'Avignon LC, Chung KK, Saffle JR, Renz EM, Cancio LC. Prevention of Combat-Related Infections Guidelines Panel. Prevention of infections associated with combat-related burn injuries. J Trauma. 2011;71:S282-9.

73. D'Avignon LC, Hogan BK, Murray CK, Loo FL, Hospenthal DR, Cancio LC, et al. Contribution of bacterial and viral infections to attributable mortality in patients with severe burns: an autopsy series. Burns. 2010;36:773-9.

74. Hospenthal DR, Murray CK, Andersen RC, Bell RB, Calhoun JH, Cancio LC, et al. Guidelines for the prevention of infections associated with combat-related injuries: 2011 update: endorsed by the Infectious Diseases Society of America and the Surgical Infection Society. J Trauma. 2011;71:S210-34.

75. Hospenthal DR, Murray CK, Andersen RC, Blice JP, Calhoun JH, Cancio LC, et al. Guidelines for the prevention of infection after combat-related injuries. J Trauma. 2008;64:S211-20.

76. Rafla K, Tredget EE. Infection control in the burn unit. Burns. 2011;37:5-15.

77. Rowley-Conwy G. Infection prevention and treatment in patients with major burn injuries. Nurs Stand. 2010;25:51-2. 54, 56-8 passim.

78. Brown TP, Cancio LC, McManus AT, Mason Jr AD. Survival benefit conferred by topical antimicrobial preparations in burn patients: a historical perspective. J Trauma. 2004;56:863-6.

79. Roberts JA, Abdul-Aziz MH, Lipman J, Mouton JW, Vinks AA, Felton TW, et al. Individualised antibiotic dosing for patients who are critically ill: challenges and potential solutions. Lancet Infect Dis. 2014;14:498-509.

80. Horvath EE, Murray CK, Vaughan GM, Chung KK, Hospenthal DR, Wade CE, et al. Fungal wound infection (not colonization) is independently associated with mortality in burn patients. Ann Surg. 2007;245:978-85.

81. Herndon DN, Tompkins RG. Support of the metabolic response to burn injury. Lancet. 2004;363:1895-902.

82. Williams FN, Herndon DN, Jeschke MG. The hypermetabolic response to burn injury and interventions to modify this response. Clin Plast Surg. 2009:36:583-96.

83. Andel H, Kamolz LP, Horauf K, Zimpfer M. Nutrition and anabolic agents in burned patients. Burns. 2003;29:592-5.

84. Abdullahi A, Jeschke MG. Nutrition and anabolic pharmacotherapies in the care of burn patients. Nutr Clin Pract. 2014;29:621-30.

85. Hart DW, Wolf SE, Chinkes DL, Beauford RB, Mlcak RP, Heggers JP, et al. Effects of early excision and aggressive enteral feeding on hypermetabolism, catabolism, and sepsis after severe burn. J Trauma. 2003;54:755-61. discussion 761-4.

86. Mosier MJ, Pham TN, Klein MB, Gibran NS, Arnoldo BD, Gamelli RL, et al. Early enteral nutrition in burns: compliance with guidelines and associated outcomes in a multicenter study. J Burn Care Res. 2011;32:104-9.

87. Mecott GA, Al-Mousawi AM, Gauglitz GG, Herndon DN, Jeschke MG. The role of hyperglycemia in burned patients: evidence-based studies. Shock. 2010;33:5-13.
88. Gore DC, Chinkes DL, Hart DW, Wolf SE, Herndon DN, Sanford AP. Hyperglycemia exacerbates muscle protein catabolism in burn-injured patients. Crit Care Med. 2002;30:2438-42.

89. Kulp GA, Tilton RG, Herndon DN, Jeschke MG. Hyperglycemia exacerbates burn-induced liver inflammation via noncanonical nuclear factor-kappaB pathway activation. Mol Med. 2012;18:948-56.

90. Cunningham-Rundles S, McNeeley DF, Moon A. Mechanisms of nutrient modulation of the immune response. J Allergy Clin Immunol. 2005;115:1119-28. quiz 1129.

91. Schwacha MG, Chaudry $\mathbb{H}$. The cellular basis of post-burn immunosuppression: macrophages and mediators. Int J Mol Med. 2002;10:239-43.

92. Ferrando AA, Chinkes DL, Wolf SE, Matin S, Herndon DN, Wolfe RR. A submaximal dose of insulin promotes net skeletal muscle protein synthesis in patients with severe burns. Ann Surg. 1999;229:11-8.

93. Hrynyk M, Neufeld RJ. Insulin and wound healing. Burns. 2014;40:1433-46.

94. Pidcoke HF, Baer LA, Wu X, Wolf SE, Aden JK, Wade CE. Insulin effects on glucose tolerance, hypermetabolic response, and circadian-metabolic protein expression in a rat burn and disuse model. Am J Physiol Regul Integr Comp Physiol. 2014;307:R1-10.

95. Pidcoke HF, Wade CE, Wolf SE. Insulin and the burned patient. Crit Care Med. 2007;35:S524-30.

96. Sakurai Y, Aarsland A, Herndon DN, Chinkes DL, Pierre E, Nguyen TT, et al. Stimulation of muscle protein synthesis by long-term insulin infusion in severely burned patients. Ann Surg. 1995;222:283-94.

97. Hart DW, Wolf SE, Ramzy PI, Chinkes DL, Beauford RB, Ferrando AA, et al. Anabolic effects of oxandrolone after severe burn. Ann Surg. 2001;233:556-64

98. Tuvdendorj D, Chinkes DL, Zhang XJ, Suman OE, Aarsland A, Ferrando A, et al. Long-term oxandrolone treatment increases muscle protein net deposition via improving amino acid utilization in pediatric patients 6 months after burn injury. Surgery. 2011;149:645-53.

99. Wolf SE, Edelman LS, Kemalyan N, Donison L, Cross J, Underwood M, et al. Effects of oxandrolone on outcome measures in the severely burned: a multicenter prospective randomized double-blind trial. J Burn Care Res. 2006;27:131-9. discussion 140-1.

100. Wolf SE, Thomas SJ, Dasu MR, Ferrando AA, Chinkes DL, Wolfe RR, et al. Improved net protein balance, lean mass, and gene expression changes with oxandrolone treatment in the severely burned. Ann Surg. 2003:237:801-10. discussion 810-1.

101. Bains JW, Crawford DT, Ketcham AS. Effect of chronic anemia on wound tensile strength: correlation with blood volume, total red blood cell volume and proteins. Ann Surg. 1966;164:243-6.

102. Agarwal P, Prajapati B, Sharma D. Evaluation of skin graft take following post-burn raw area in normovolaemic anaemia. Indian J Plast Surg. 2009:42:195-8.

103. Namdar T, Stollwerck PL, Stang FH, Eisenbeiss W, Siemers F, Mailander P, et al. Impact of hypernatremia on burn wound healing: results of an exploratory, retrospective study. Ostomy Wound Manage. 2011;57:30-4.

104. Nitzschke SL, Aden JK, Serio-Melvin ML, Shingleton SK, Chung KK, Waters JA, et al. Wound healing trajectories in burn patients and their impact on mortality. J Burn Care Res. 2014;35:474-9.

105. Desai MH, Herndon DN, Broemeling L, Barrow RE, Nichols Jr RJ, Rutan RL. Early burn wound excision significantly reduces blood loss. Ann Surg. 1990;211:753-9. discussion 759-62.

106. Herndon DN, Barrow RE, Rutan RL, Rutan TC, Desai MH, Abston S. A comparison of conservative versus early excision. Therapies in severely burned patients. Ann Surg. 1989;209:547-52. discussion 552-3.

107. Saaiq M, Zaib S, Ahmad S. Early excision and grafting versus delayed excision and grafting of deep thermal burns up to $40 \%$ total body surface area: a comparison of outcome. Ann Burns Fire Disasters. 2012;25:143-7.

108. Vinita P, Khare NA, Chandramouli M, Nilesh S, Sumit B. Comparative analysis of early excision and grafting vs delayed grafting in burn patients in a developing country. J Burn Care Res. 2014; doi:10.1097/BCR.0b013e31827e4ed6.

109. Ong YS, Samuel M, Song C. Meta-analysis of early excision of burns. Burns. 2006;32:145-50.

110. Schwanholt C, Greenhalgh DG, Warden GD. A comparison of full-thickness versus split-thickness autografts for the coverage of deep palm burns in the very young pediatric patient. J Burn Care Rehab. 1993;14:29-33.

111. Akan M, Yildirim S, Misirlioglu A, Ulusoy G, Akoz T, Avci G. An alternative method to minimize pain in the split-thickness skin graft donor site. Plast Reconstruct Surg. 2003;111:2243-9. 
112. Voineskos SH, Ayeni OA, McKnight L, Thoma A. Systematic review of skin graft donor-site dressings. Plast Reconstruct Surg. 2009;124:298-306.

113. Hermans MH. Preservation methods of allografts and their (lack of) influence on clinical results in partial thickness burns. Burns. 2011;37:873-81.

114. Hermans MH. Porcine xenografts vs. (cryopreserved) allografts in the management of partial thickness burns: is there a clinical difference? Burns. 2014;40:408-15.

115. Ehrenreich M, Ruszczak Z. Tissue-engineered temporary wound coverings. Important options for the clinician. Acta Dermatovenerol Alp Pannonica Adriat. 2006:15:5-13.

116. Ehrenreich M, Ruszczak Z. Update on tissue-engineered biological dressings. Tissue Eng. 2006;12:2407-24.

117. Groeber F, Holeiter M, Hampel M, Hinderer S, Schenke-Layland K. Skin tissue engineering - in vivo and in vitro applications. Clin Plast Surg. 2012:39:33-58

118. Mansbridge J. Skin tissue engineering. J Biomater Sci Polym Ed. 2008;19:955-68

119. Mansbridge JN. Tissue-engineered skin substitutes in regenerative medicine. Curr Opin Biotechnol. 2009;20:563-7.

120. Catalano E, Cochis A, Varoni E, Rimondini L, Azzimonti B. Tissue-engineered skin substitutes: an overview. J Artif. 2013:16:397-403.

121. Shevchenko RV, James SL, James SE. A review of tissue-engineered skin bioconstructs available for skin reconstruction. J R Soc Interface. 2010;7:229-58.

122. Atiyeh BS, Costagliola M. Cultured epithelial autograft (CEA) in burn treatment: three decades later. Burns. 2007;33:405-13.

123. Fang T, Lineaweaver WC, Sailes FC, Kisner C, Zhang F. Clinical application of cultured epithelial autografts on acellular dermal matrices in the treatment of extended burn injuries. Ann Plast Surg. 2014;73:509-15.

124. Jeschke MG, Finnerty CC, Shahrokhi S, Branski LK, Dibildox M, Organization $A B A$, et al. Wound coverage technologies in burn care: novel techniques J Burn Care Res. 2013;34:612-20.

125. Supp DM, Boyce ST. Engineered skin substitutes: practices and potentials. Clin Dermatol. 2005;23:403-12.

126. Kampmann A, Lindhorst D, Schumann P, Zimmerer R, Kokemuller $H$, Rucker $M$, et al. Additive effect of mesenchymal stem cells and VEGF to vascularization of PLGA scaffolds. Microvasc Res. 2013;90:71-9.

127. Park KM, Gerecht S. Harnessing developmental processes for vascular engineering and regeneration. Development. 2014;141:2760-9.

128. Broussard KC, Powers JG. Wound dressings: selecting the most appropriate type. Am J Clin Dermatol. 2013:14:449-59.

129. Wasiak J, Cleland H, Campbell F, Spinks A. Dressings for superficial and partial thickness burns. Cochrane Database Syst Rev. 2013;3, CD002106.

130. Aziz Z, Abu SF, Chong NJ. A systematic review of silver-containing dressings and topical silver agents (used with dressings) for burn wounds. Burns. 2012:38:307-18

131. Nikkhah D, Gilbert P, Booth S, Dheansa B. Should we be using silver based compounds for donor site dressing in thermal burns? Burns. 2013;39:1324-5.

132. Abboud EC, Legare TB, Settle JC, Boubekri AM, Barillo DJ, Marcet JE, et al. Do silver-based wound dressings reduce pain? A prospective study and review of the literature. Burns. 2014:40:S40-7.

133. Navarro FA, Stoner ML, Park CS, Huertas JC, Lee HB, Wood FM, et al. Sprayed keratinocyte suspensions accelerate epidermal coverage in a porcine microwound model. J Burn Care Rehab. 2000;21:513-8.

134. Wood FM, Kolybaba ML, Allen P. The use of cultured epithelial autograft in the treatment of major burn wounds: eleven years of clinical experience. Burns. 2006;32:538-44.

135. Wood FM, Kolybaba ML, Allen P. The use of cultured epithelial autograft in the treatment of major burn injuries: a critical review of the literature. Burns. 2006:32:395-401.

136. Tenenhaus M, Rennekampff HO. Surgical advances in burn and reconstructive plastic surgery: new and emerging technologies. Clin Plast Surg. 2012;39:435-43.

137. Tausche AK, Skaria M, Bohlen L, Liebold K, Hafner J, Friedlein $H$, et al. An autologous epidermal equivalent tissue-engineered from follicular outer root sheath keratinocytes is as effective as split-thickness skin autograft in recalcitrant vascular leg ulcers. Wound Repair Regen. 2003;11:248-52.

138. Bisson F, Rochefort E, Lavoie A, Larouche D, Zaniolo K, Simard-Bisson C, et al. Irradiated human dermal fibroblasts are as efficient as mouse fibroblasts as a feeder layer to improve human epidermal cell culture lifespan. Int J Mol Sci. 2013:14:4684-704.
139. Idrus RB, Rameli MA, Low KC, Law JX, Chua KH, Latiff MB, et al. Full-thickness skin wound healing using autologous keratinocytes and dermal fibroblasts with fibrin: bilayered versus single-layered substitute. Adv Skin Wound Care. 2014:27:171-80.

140. Auxenfans C, Menet V, Catherine Z, Shipkov H, Lacroix P, Bertin-Maghit M, et al. Cultured autologous keratinocytes in the treatment of large and deep burns: a retrospective study over 15 years. Burns. 2015;41:71-9.

141. Auxenfans C, Shipkov H, Bach C, Catherine Z, Lacroix P, Bertin-Maghit M, et al. Cultured allogenic keratinocytes for extensive burns: a retrospective study over 15 years. Burns. 2014:40:82-8.

142. van der Veer WM, Bloemen MC, Ulrich MM, Molema G, van Zuijlen PP, Middelkoop E, et al. Potential cellular and molecular causes of hypertrophic scar formation. Burns. 2009:35:15-29.

143. Lewis CJ. Stem cell application in acute burn care and reconstruction. J Wound Care. 2013:22:7-8. 10, 12-6.

144. Badiavas EV. The potential of bone marrow cells to orchestrate homeostasis and healing in skin. Blood Cells Mol Dis. 2004;32:21-3.

145. Badiavas EV, Abedi M, Butmarc J, Falanga V, Quesenberry P. Participation of bone marrow derived cells in cutaneous wound healing. J Cell Physiol. 2003;196:245-50

146. Sasaki M, Abe R, Fujita Y, Ando S, Inokuma D, Shimizu H. Mesenchymal stem cells are recruited into wounded skin and contribute to wound repair by transdifferentiation into multiple skin cell type. J Immunol. 2008;180:2581-7

147. Bey E, Prat M, Duhamel P, Benderitter M, Brachet M, Trompier F, et al. Emerging therapy for improving wound repair of severe radiation burns using local bone marrow-derived stem cell administrations. Wound Repair Regen. 2010;18:50-8.

148. Kim WS, Park BS, Sung JH, Yang JM, Park SB, Kwak SJ, et al. Wound healing effect of adipose-derived stem cells: a critical role of secretory factors on human dermal fibroblasts. J Dermatol Sci. 2007;48:15-24.

149. Nakagami H, Maeda K, Morishita R, Iguchi S, Nishikawa T, Takami Y, et al. Novel autologous cell therapy in ischemic limb disease through growth factor secretion by cultured adipose tissue-derived stromal cells. Arterioscler Thromb Vasc Biol. 2005;25:2542-7

150. Kurata S, Itami S, Terashi H, Takayasu S. Successful transplantation of cultured human outer root sheath cells as epithelium. Ann Plast Surg. 1994;33:290-4.

151. Navsaria HA, Ojeh NO, Moiemen N, Griffiths MA, Frame JD. Reepithelialization of a full-thickness burn from stem cells of hair follicles micrografted into a tissue-engineered dermal template (Integra). Plast Reconstruct Surg. 2004;113:978-81.

152. Trottier V, Marceau-Fortier G, Germain L, Vincent C, Fradette J. IFATS collection: using human adipose-derived stem/stromal cells for the production of new skin substitutes. Stem Cells. 2008;26:2713-23.

153. Natesan S, Wrice NL, Baer DG, Christy RJ. Debrided skin as a source of autologous stem cells for wound repair. Stem Cells. 2011;29:1219-30.

154. Chan RK, Zamora DO, Wrice NL, Baer DG, Renz EM, Christy RJ, et al. Development of a vascularized skin construct using adipose-derived stem cells from debrided burned skin. Stem Cells Int. 2012;2012:841203.

155. Williams JF, King BT, Aden JK, Serio-Melvin M, Chung KK, Fenrich CA, et al. Comparison of traditional burn wound mapping with a computerized program. J Burn Care Res. 2013;34:e29-35.

156. Brown TS, Safford S, Caramanica J, Elster EA. Biomarker use in tailored combat casualty care. Biomark Med. 2010;4:465-73.

157. Hawksworth JS, Stojadinovic A, Gage FA, Tadaki DK, Perdue PW, Forsberg J, et al. Inflammatory biomarkers in combat wound healing. Ann Surg. 2009:250:1002-7.

158. Hahm G, Glaser JJ, Elster EA. Biomarkers to predict wound healing: the future of complex war wound management. Plast Reconstruct Surg. 2011:127:21S-6S

159. Chromy BA, Eldridge A, Forsberg JA, Brown TS, Kirkup BC, Elster E, et al. Proteomic sample preparation for blast wound characterization. Proteome Sci. 2014;12:10.

160. Chromy BA, Eldridge A, Forsberg JA, Brown TS, Kirkup BC, Jaing $C$, et al. Wound outcome in combat injuries is associated with a unique set of protein biomarkers. J Transl Med. 2013;11:281.

161. Forsberg JA, Potter BK, Polfer EM, Safford SD, Elster EA. Do inflammatory markers portend heterotopic ossification and wound failure in combat wounds? Clin Orthop Relat Res. 2014;472:2845-54.

162. Mikhal'chik EV, Piterskaya JA, Budkevich LY, Pen'kov LY, Facchiano A, De Luca C, et al. Comparative study of cytokine content in the plasma and 
wound exudate from children with severe burns. Bull Exp Biol Med. 2009;148:771-5.

163. Widgerow AD, King K, Tussardi IT, Banyard DA, Chiang R, Awad A, et al. The burn wound exudate - an under-utilized resource. Burns. 2015;41:11-7.

164. Prager MD, Sabeh F, Baxter CR, Atiles L, Hartline B. Dipeptidyl peptidase IV and aminopeptidase in burn wound exudates: implications for wound healing. J Trauma. 1994;36:629-33.

165. Mauskar NA, Sood S, Travis TE, Matt SE, Mino MJ, Burnett MS, et al. Donor site healing dynamics: molecular, histological, and noninvasive imaging assessment in a porcine model. J Burn Care Res. 2013:34:549-62.

166. Kaiser M, Yafi A, Cinat M, Choi B, Durkin AJ. Noninvasive assessment of burn wound severity using optical technology: a review of current and future modalities. Burns. 2011;37:377-86.

167. Arbab MH, Dickey TC, Winebrenner DP, Chen A, Klein MB, Mourad PD. Terahertz reflectometry of burn wounds in a rat model. Biomed Opt Express. 2011;2:2339-47.

168. Cross KM, Leonardi L, Gomez M, Freisen JR, Levasseur MA, Schattka BJ, et al. Noninvasive measurement of edema in partial thickness burn wounds. J Burn Care Res. 2009;30:807-17.

169. Cross KM, Leonardi L, Payette JR, Gomez M, Levasseur MA, Schattka BJ, et al. Clinical utilization of near-infrared spectroscopy devices for burn depth assessment. Wound Repair Regen. 2007;15:332-40.

170. Nguyen JQ, Crouzet C, Mai T, Riola K, Uchitel D, Liaw LH, et al. Spatial frequency domain imaging of burn wounds in a preclinical model of graded burn severity. J Biomed Opt. 2013;18:66010.

171. Sowa MG, Leonardi L, Payette JR, Cross KM, Gomez M, Fish JS. Classification of burn injuries using near-infrared spectroscopy. J Biomed Opt. 2006;11:054002.

172. Sowa MG, Leonardi L, Payette JR, Fish JS, Mantsch HH. Near infrared spectroscopic assessment of hemodynamic changes in the early post-burn period. Burns. 2001;27:241-9.

173. Devgan L, Bhat S, Aylward S, Spence RJ. Modalities for the assessment of burn wound depth. J Burns Wounds. 2006;5, e2.

174. Pape SA, Skouras CA, Byrne PO. An audit of the use of laser Doppler imaging (LDI) in the assessment of burns of intermediate depth. Burns. 2001;27:233-9.

175. Hoeksema H, Van de Sijpe K, Tondu T, Hamdi M, Van Landuyt K, Blondeel P, et al. Accuracy of early burn depth assessment by laser Doppler imaging on different days post burn. Burns. 2009;35:36-45.

176. Ogden CL, Carroll MD, Kit BK, Flegal KM. Prevalence of childhood and adult obesity in the United States, 2011-2012. JAMA. 2014;311:806-14.

177. Goutos I, Sadideen H, Pandya AA, Ghosh SJ. Obesity and burns. J Burn Care Res. 2012;33:471-82.

178. Neaman KC, Andres LA, McClure AM, Burton ME, Kemmeter PR, Ford RD. A new method for estimation of involved BSAs for obese and normal-weight patients with burn injury. J Burn Care Res. 2011;32:421-8.

179. Liodaki E, Senyaman O, Stollwerck PL, Mollmeier D, Mauss KL, Mailander $\mathrm{P}$, et al. Obese patients in a burn care unit: a major challenge. Burns. 2014:40:1738-42.

180. Keck M, Lumenta DB, Andel H, Kamolz LP, Frey M. Burn treatment in the elderly. Burns. 2009;35:1071-9.

181. Lewandowski R, Pegg S, Fortier K, Skimmings A. Burn injuries in the elderly. Burns. 1993;19:513-5.

182. Hunt JL, Purdue GF. The elderly burn patient. Am J Surg. 1992;164:472-6.

183. Williams GJ, Herndon DN. Modulating the hypermetabolic response to burn injuries. J Wound Care. 2002;11:87-9.

184. Roberts G, Lloyd M, Parker M, Martin R, Philp B, Shelley O, et al. The Baux score is dead. Long live the Baux score: a 27 -year retrospective cohort study of mortality at a regional burns service. J Trauma Acute Care Surg. 2012;72:251-6.

185. Nordlund MJ, Pham TN, Gibran NS. Micronutrients after burn injury: a review. J Burn Care Res. 2014;35:121-33.

186. Pintaudi AM, Tesoriere L, D'Arpa N, D'Amelio L, D'Arpa D, Bongiorno A, et al. Oxidative stress after moderate to extensive burning in humans. Free Radic Res. 2000;33:139-46.

187. Vinha PP, Martinez EZ, Vannucchi H, Marchini JS, Farina Jr JA, Jordao Jr AA et al. Effect of acute thermal injury in status of serum vitamins, inflammatory markers, and oxidative stress markers: preliminary data. J Burn Care Res. 2013;34:e87-91.

188. Aida T, Murata J, Asano G, Kanda Y, Yoshino Y. Effects of polyprenoic acid on thermal injury. Br J Exp Pathol. 1987;68:351-8.
189. Nickle SB, Peterson N, Peterson M. Updated physician's guide to the offlabel uses of oral isotretinoin. J Clin Aesthet Dermatol. 2014;7:22-34.

190. Dematte MF, Gemperli R, Salles AG, Dolhnikoff M, Lancas T, Saldiva PH, et al. Mechanical evaluation of the resistance and elastance of post-burn scars after topical treatment with tretinoin. Clinics. 2011;66:1949-54.

191. Salles AG, Gemperli R, Toledo PN, Ferreira MC. Combined tretinoin and glycolic acid treatment improves mouth opening for postburn patients. Aesthet Plast Surg. 2006;30:356-62.

192. Macias-Barragan J, Sandoval-Rodriguez A, Navarro-Partida J, ArmendarizBorunda J. The multifaceted role of pirfenidone and its novel targets. Fibrogenesis Tissue Repair. 2010;3:16.

193. Jung Kl, Choi JS, Kim HK, Shin SY. Effects of an anti-transforming growth factor-beta agent (pirfenidone) on strabismus surgery in rabbits. Curr Eye Res. 2012;37:770-6.

194. Zhong H, Sun G, Lin X, Wu K, Yu M. Evaluation of pirfenidone as a new postoperative antiscarring agent in experimental glaucoma surgery. Invest Ophthalmol Vis Sci. 2011;52:3136-42.

195. Chowdhury S, Guha R, Trivedi R, Kompella UB, Konar A, Hazra S. Pirfenidone nanoparticles improve corneal wound healing and prevent scarring following alkali burn. PLoS One. 2013;8, e70528.

196. Cianci $P$, Sato R. Adjunctive hyperbaric oxygen therapy in the treatment of thermal burns: a review. Burns. 1994;20:5-14

197. Cianci P, Williams C, Lueders H, Lee H, Shapiro R, Sexton J, et al. Adjunctive hyperbaric oxygen in the treatment of thermal burns. An economic analysis. J Burn Care Rehab. 1990;11:140-3.

198. Selcuk CT, Ozalp B, Durgun M, Tekin A, Akkoc MF, Alabalik U, et al. The effect of hyperbaric oxygen treatment on the healing of burn wounds in nicotinized and nonnicotinized rats. J Burn Care Res. 2013;34:e237-43.

199. Cianci P, Slade Jr JB, Sato RM, Faulkner J. Adjunctive hyperbaric oxygen therapy in the treatment of thermal burns. Undersea Hyperb Med. 2013:40:89-108

200. Eskes A, Vermeulen H, Lucas C, Ubbink DT. Hyperbaric oxygen therapy for treating acute surgical and traumatic wounds. Cochrane Database Syst Rev. 2013;12, CD008059.

201. Eskes AM, Ubbink DT, Lubbers MJ, Lucas C, Vermeulen H. Hyperbaric oxygen therapy: solution for difficult to heal acute wounds? Systematic review. World J Surg. 2011;35:535-42.

202. Wolf SE, Tompkins RG, Herndon DN. On the horizon: research priorities in burns for the next decade. Surg Clin North Am. 2014;94:917-30. 